\title{
A Retrospective Overview of Factors that Influence Guinea Worm Epidemic in Northern Region of Ghana
}

\author{
Nicholas N. Yembilah \\ Department of Environment and Resource Studies, \\ University for Development Studies, Ghana \\ Email:yembilahnicholas@gmail.com \\ DOI//http://dx.doi.org/10.4314/gjds.v16i1.6
}

\begin{abstract}
This article retrospectively examines the factors which caused Guinea Worm Disease (Dracunculiasis) to spread to epidemic levels, so as to serve as the basis for formulating a national preventive agenda to reinforce the preventive measures which have been put in place to prevent the disease from re-emerging. The hybrid conceptual framework of disease diffusion and disease ecology was used. The mixed method research design was used to collect data from a total of 11 administrative districts. Primary data was obtained from a total of 860 respondents. To achieve a representative distribution of respondents, they were proportionately selected with respect to the populations of their respective districts. A key Informant interview was conducted. It was found that the major cause of the disease was attributed to poor access to potable water. Others were difficulty in getting ground water, populations preferring surface sources of drinking water, all year round contact with perennial surface sources of drinking water, and the "knee deep level" culture of fetching clean water from surface sources. It was concluded that cultural practices, environmental conditions, climatic influences, and real/imagined perceptions on the quality of water influenced the spread of the disease. It was recommended that government health institutions should make efforts at determining the factors that make populations vulnerable to diseases. The policy implication is that government will have to commit resources to provide people with the information and equipment they need to interact with their biophysical environment.
\end{abstract}

Keywords: Drinking Water, Underground Water, Climate, Culture, Epidemic 


\section{INTRODUCTION}

Ever since Guinea Worm Disease (GWD), scientifically known as Dracunculiasis, was reported in Ghana (Waddy, 1956) it was not until the early to mid-1980s that efforts were made to control it at different levels of intervention. During this period research showed that a set of factors was responsible for the spread of the disease in the Northern Region. When it was established that there was an outbreak of a guinea worm epidemic in the Northern Region of Ghana (Centres for Disease Control [CDC], 1989), attention was drawn to the possible factors in the region which made the region vulnerable to the disease. Since Guinea worm is a water-borne disease the sources of water supply during the epidemic was examined to unearth the factors which made the disease spread (Bugri, 1981, 1993). This article seeks to undertake a retrospective examination of the factors which caused the disease to spread to epidemic levels in the Northern Region in order to establish a national preventive agenda to reinforce and advance the permanent preventive measures which have been put in place to forestall the disease from re-emerging since its eradication in Ghana in 2015 (CDC, 2016).

\section{The Hybrid Conceptual Framework of Disease Diffusion and Disease Ecology}

Stock (1976) and Lucas and Giles' (1973) models of diffusion and disease ecology were merged to produce a conceptual framework of disease diffusion and disease ecology. Gregory explained in Johnson et al. (2000), that disease could spread over space or meet resistance through peoples' behaviour. The conceptual framework suggests that a disease spreads because resistance to it in the form of information flow is limited; thus creating barriers to regulate people's behaviour at the adoption surface. When knowledge of a disease increases people develop resistance by building socio-cultural barriers to regulate their interaction with the infectious agent of the disease. The conceptual framework explains that, the spread of a disease occurs between the transmission cycle and the triangle of disease ecology. The type of responses people make toward a disease and the physical environment in which they live influences the survival and transmission of disease to the wider society.

In this conceptual framework a disease enters a community and spreads through biological, physical, and social factors acting together to ensure the survival, and spread of the disease. The triangle of disease ecology is the agent-host factor relation. The agent-host factor relation is the intermediate factor that makes it possible for an infection to occur. The host to host factor relation is the stage of the man-physical environment relationship that permits a disease to infect people. 
This framework is useful for explaining disease causation for communicable diseases including GWD. The inherent weakness of the hybrid conceptual framework of disease diffusion and disease ecology lies in the fact that it cannot explain disease causation for non-communicable diseases and hereditary diseases, because the cause of these category of diseases are not linked to man-environment relationships. The framework was adopted because it offered an environmental, social, and human dimension to explain the cause and spread of communicable diseases over space and shows the window through which the transmission of communicable diseases can be interrupted.

When an infectious agent survives it spreads beyond the borders of initial infective communities. It is between the cycles of external diffusion and retransmission between infective communities that interventions are introduced to break the chain of transmission between the infectious agent and the human host. The conceptual framework as discussed is shown in Figure 1.

Cyclical Expansion and Retreat of Disease Diffusion

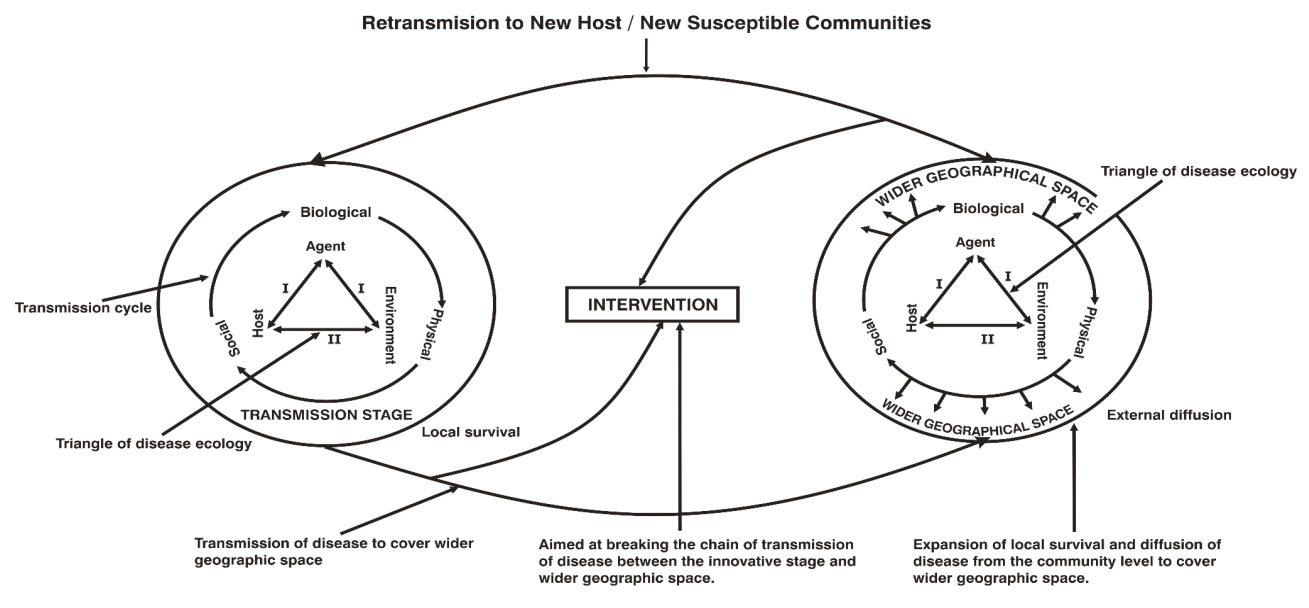

Source: Author's Construct derived from Lucas and Giles (1973) and Stock (1976)

Figure 1: Conceptual frame work of disease diffusion

Source: Author's construct derived from Lucas and Giles (1973) and Stock (1976) 
When the life cycle of a disease causing agent is known, steps can be taken to break the chain of transmission of the disease to humans. This is done by establishing the points at which humans come into contact with the infectious agent of the disease. The chain of transmission of the disease can then be interrupted by modifying people's social interactions with their physical environment or the infectious agent of the disease. So that in the case of GWD, people's social interactions with their environment and the infectious agent of the disease should be modified by preventing people from coming into contact with surface sources of drinking water, chemically treating surface sources of drinking water, and treating harvested surface water before drinking. By doing this it would be possible to achieve the ideal situation of Uzbekistan in 1932 when GWD was eliminated in humans (WHO, 1998; Isaev, 1956), which was the non-return of guinea worm infections even though majority of rural areas which were affected by the disease did not have access to potable water. The overall implication of such a situation would mean that the Guinea Worm Eradication Programme has succeeded in isolating agent-host factor relationships of the infectious agent of the disease, physical, and socio-cultural factors of the triangle of disease ecology into their respective environments by controlling the way people relate with the infectious agent of the disease and their physical environment.

\section{METHODOLOGY}

\section{Study Design and Sampling}

Recognising that qualitative and quantitative methods have limitations, the mixed method approach (combining qualitative and quantitative methods) was relied on to collect data from a total of 11 administrative districts in the Northern Region which were defined to be guinea worm endemic district. Mixing was used to neutralise the effect of or cancel out biases inherent in each method and to integrate quantitative data with qualitative data (supporting statistical results with qualitative quotes) which would make results from both methods to reinforce each other (Creswell, 2009). Questionnaire surveys was administered to respondents in the study area. Focus Group Discussions (FGDs) were held with some members of communities in which questionnaire was administered. Key informant interview was held with Ghana's first Guinea Worm Eradication Programme National Coordinator. This was to obtain first-hand information on the guinea worm epidemic. 


\section{Data Collection and Analysis}

The adult population of the Northern Region, which was set to be between the ages 15 and 6o+ was estimated by the Ghana Statistical Service to be $61.7 \%$ of the region's population. The sample population for the study was therefore determined by the using the adult population percentage of the region to extract the adult population for the study area from the 2010 Population and Housing Census record for the study area which was 1, 137, 244 (GSS, 2013). The adult population which was a $61.7 \%$ estimate of the population of the study area was therefore put at 701680 . Krejcie and Morgan's (1970) work on Determining Sample Size for Research Activities was used a guide to determine the sample population for the study area, using the adult estimated population of 701680 . They determined that the ideal sample size for a population size of 1 ooo ooo is 348 . Therefore the ideal sample size of the study area with an adult population of 701680 would be 270 . However, considering the fact that some districts would have very low proportionate sample sizes for the study area, adjustments were made to the proportionate sample sizes for each district to achieve a sufficient representation of respondents for each district. The adjustments made for each district's sample size resulted in the study area having a sample population of 860 respondents.

Data was collected from 11 administrative districts in the Northern Region which were defined as guinea worm endemic areas. Primary data was obtained over a period of seven months. Respondents in each district were broadly categorised into Household heads and Opinion leaders. Respondents were put into the following categories because household heads are mostly farmers and domestic hands and were considered to be those who were directly and indirectly affected by the epidemic and could therefore relate the effects of the epidemic and the effect of the Guinea Worm Eradication Programme (GWEP) on their social and economic needs. Residents were included in this category because the epidemic directly or indirectly affected other community members. The views of opinion leaders was sought because they were considered to belong to a category of people who could confirm the views of household heads on the epidemic and the role the programme has played in alleviating their plight. Respondents in these categories were proportionately distributed according to the populations of their respective districts and were randomly selected and interviewed. Respondents who were willing to participate by responding to questions were randomly selected and interviewed. Table 1 shows the study districts and the number of respondents selected for each district (GGWEP/GHS, 2012; CDC, 2005). To achieve a representative distribution of questionnaire over the study area, respondents' were proportionately distributed according to the population of each district and randomly selected and interviewed. 
Table 1: Sample population of the study area

\begin{tabular}{|l|l|l|l|}
\hline District & Household head & Opinion Leaders & Total Percent \\
\hline Yendi & 128 & 27 & 15518 \\
\hline Savelugu-Nanton & 80 & 15 & 9511 \\
\hline East Gonja & 82 & 12 & 9411.2 \\
\hline Central Gonja & 49 & 9 & 586.7 \\
\hline Zabzugu-Tatale & 73 & 15 & 8810.2 \\
\hline Nanumba North & 41 & 8 & 495.7 \\
\hline Nanumba South & 64 & 9 & 738.4 \\
\hline Gushiegu & 59 & 11 & 708.2 \\
\hline Karaga & 58 & 8 & 667.6 \\
\hline Tolon & 39 & 6 & 455.2 \\
Kumbungu & 59 & 8 & 677.8 \\
\hline Total & & & 860100 \\
\hline
\end{tabular}

Source: Field Survey, 2016

A key Informant interview was held with the First National Coordinator of the Guinea Worm Eradication Programme to unearth how sources of drinking water predisposed people to the disease. Also Focus Group Discussions were held with 22 focus groups. Each district had two groups, one for males and the other for females. This was to obtain gender related responses from each group on the effect of the epidemic.

Secondary data on sources of drinking water was classified under the following headings: pipe borne, borehole, well, dam, dugout, lagoon, river, rainwater, spring, and canal (GSS, 2008-2017). These headings were further classified into potable and un-potable sources of drinking water. Dams, ponds, dugouts, rivers, springs and rain water were classified as un-potable sources of drinking water, while water from pipes, boreholes, and wells were classified as potable sources of drinking water. Wells were classified as potable sources because they are mostly owned by individuals and are within the precincts of their homes and they build concrete enclosures at the mouth of their wells to prevent pollutants from entering. Data was presented using tables, maps, graphs, simple statistics and chi-square to explain trends between sources of drinking water and factors which caused the disease to spread in the region. 


\section{RESULTS AND DISCUSSION}

\section{Demographic Characteristics of Respondents}

A total of 860 respondents comprising $85.12 \%$ (732) household heads and $14.88 \%$ (128) opinion leaders were interviewed. Responses were close and open ended. Responses were entered on SPSSv2o to generate frequencies, and chi-square tests. Figure 2 below shows the age distribution of respondents.

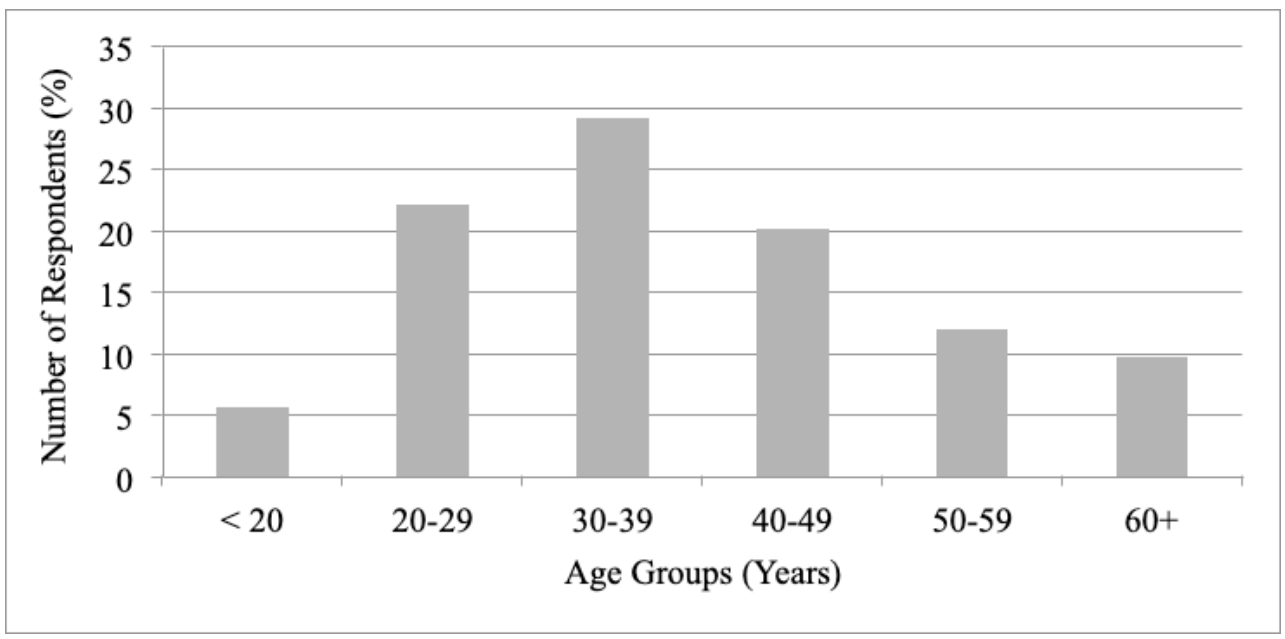

Figure 2: Distribution of respondents by age

Source: Field Survey, September 2016

Figure 2 shows that majority of respondents - 29.2\% (251) were between the ages of 30 and 39. With regard to the distribution of respondents by sex, 71\% (611) were male, and $29 \%$ (249) were female. The problem of gender bias with respect to males over females was catered for by holding Focus Group Discussions which was restricted to gender specific focus groups in each district. The educational profile of respondents in Figure 3 showed that majority of respondents were illiterate $-75.7 \%$ (650), with 23.9\% (205) having acquired formal education. 


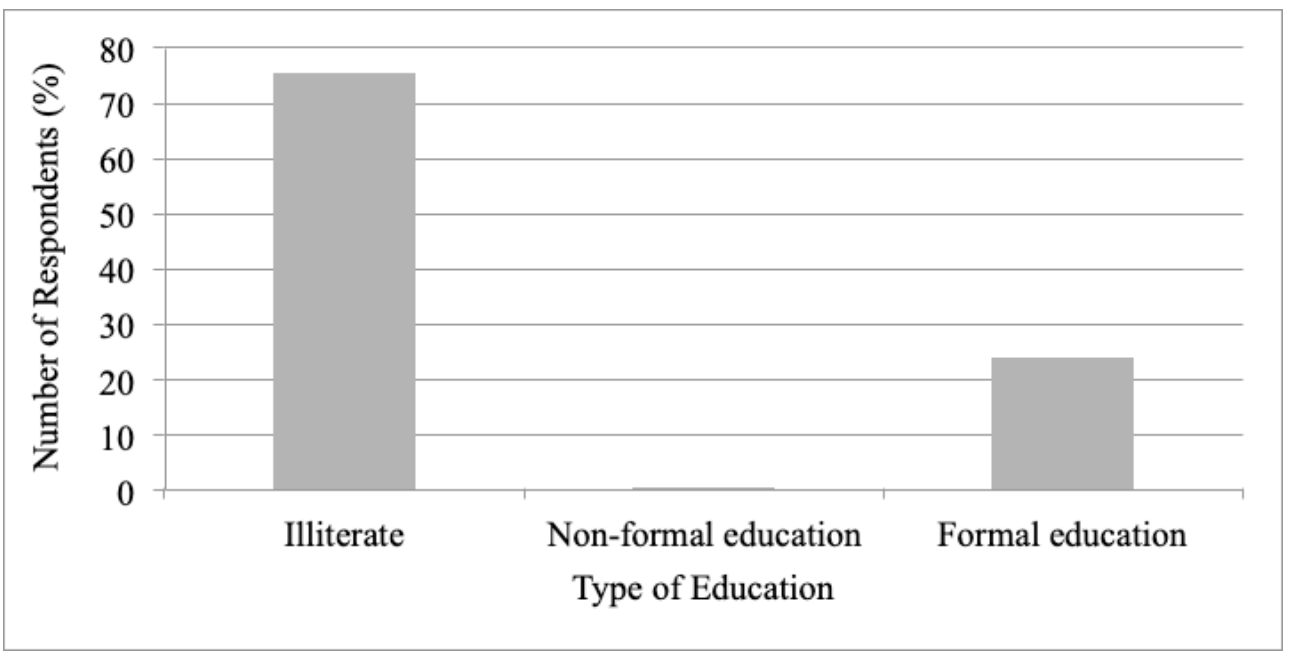

\section{Figure 3: Educational characteristics of respondents}

Source: Field Survey, September 2016

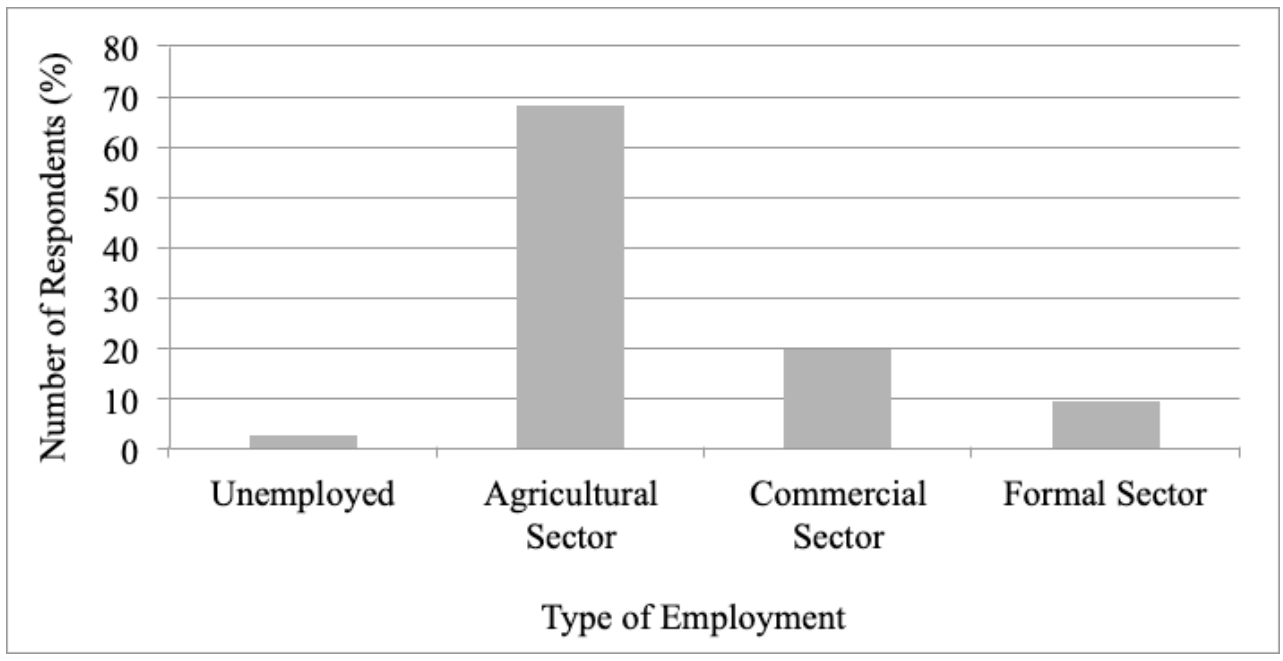

\section{Figure 4: Occupational characteristics of respondents}

Source: Field Survey, September 2016

Figure 4 indicated that majority of respondents $-68.1 \%$ (586) are employed in the agricultural sector, while 9.3\% (80) were employed in the formal sector, and $2.5 \%$ were unemployed. 


\section{Knowledge of Cause of the Guinea Worm Epidemic}

In interviewing respondents to find out if they knew the factors which caused the guinea worm epidemic in the Northern Region majority (70.7\%) attributed the cause of the disease to poor access to potable water. The rest attributed the cause of the disease to ignorance, bad sanitation and superstitious beliefs. With regard to knowledge of the cause of the epidemic by respondent category $77.4 \%$ of household heads/residents and $78.2 \%$ of opinion leaders attributed the cause of the epidemic to poor access to potable water. Some $9.8 \%$ of household heads and $7.5 \%$ of opinion leaders attributed the cause of the epidemic to lack of knowledge on the cause of the disease and how to avoid it. Respondent's knowledge of the cause of the epidemic by age revealed that respondents from all age groups with an average of $79 \%$ for each age group indicated poor access to potable water as being responsible for the outbreak of the epidemic. The remaining responses attributed the cause of the epidemic to lack of knowledge, bad sanitation practices, and superstitious beliefs. Respondents' knowledge of the cause of the epidemic by sex indicated that $84.2 \%$ females and $75 \%$ males attributed the cause of the epidemic to poor access to potable water. Respondents who attributed the epidemic to lack of knowledge, bad sanitation and superstitious beliefs had an average of $7 \%$ of both sexes subscribing to this view.

Respondents' knowledge of the cause of the epidemic by education revealed that all respondents with non-formal education (100\%), those with formal education (83.9\%), and illiterate (75.5\%) attributed the cause of the epidemic to poor access to good drinking water. With regard to the cause of the disease by occupation, it was found that all the unemployed (100\%), majority of the respondents in the formal sector (90\%), 82.4\% from the commercial sector, and $74.2 \%$ from the agricultural sector attributed the cause of the epidemic to poor access to potable water. The remaining responses were almost evenly distributed between respondents' in the agricultural, commercial, formal, and unemployed sectors with each having an average of $6.5 \%$.

On the question of what respondents thought was responsible for the epidemic by district, it was found that respondents from all the endemic districts with an average of $87.7 \%$ of respondent from each district, with the exception of the Zabzugu-Tatale district, indicated poor access to potable water as being responsible for the epidemic. However, the Zabzugu-Tatale district did not have respondents indicating poor access to potable water as being responsible for the outbreak of the epidemic. 
The statistical relevance of knowledge of the cause of the epidemic with respect to respondent category, age, gender, education, occupation, and district was subjected to Pearson's Chi square test and it was found that at a significance level of 0.05 the p-values for respondent category, age, occupation, and district are significantly related to knowledge of the cause of the epidemic as these variables had values less than 0.05 . However, knowledge of the cause of the epidemic at the same significance level was found to be unrelated to gender and education as these variables had p-values higher than 0.05 .

These responses on knowledge of the cause of GWD were confirmed by the findings of Boelee, Cecchi, and Kone's (2009) health impacts of small reservoirs in Burkina Faso which indicated that in rural areas where access to drinking water is difficult, small reservoirs become an important source of water supply. In some areas most villages have wells that dry out so fast that people have to use water from small reservoirs which exposes the surrounding population to water borne diseases. Their findings were further supported by Laari, Kpienta, and Aabeyir's (2013) work on towards guinea worm eradication in Savelugu-Nanton District Ghana: A spatio-temporal approach where they found that populations in the district got infections of the disease as a result of people depending on ponds and dams for drinking water; lack of effective dam guides to prevent people with guinea worm from coming into contact with surface sources of drinking; and the drying up of wells and boreholes which compelled most people to depend on surface sources of drinking water.

\section{Geological and Hydro-geological Factor}

The hydro-geological formations of ethnic areas in which GWD was endemic was examined with respect to the following:

(i) Obosum and Oti beds; and, (ii) Upper Voltain (Carrier et al., 2006). The most common of these geological formations is the Obusum and Oti beds. It is extensively distributed in ethnic areas in which Guinea worm was endemic. For instance the Obosum and Oti beds geological formation occurs throughout the Dagomba, Gonja, Nanumba, Konkomba, and Chekosi areas which were endemic foci of the disease (Bannerman, 1990). The coincidence of the widespread distribution of Obosum and Oti beds in the former guinea worm endemic areas of the region led to speculation that there was a relation between the prevalence of the disease in these ethnic areas and the occurrence of the Obusum and Oti beds (Kwei, 1997).

The Obusum and Oti beds geological formation also occurs in ethnic areas in which the disease was unknown. For example among the Mamprusi, the Bimoba, some parts of Konkomba and the Basaari. Some Upper Voltain formations are distributed 
in parts of Gonja, Mamprusi, Bimoba, and Konkomba ethnic areas. In determining the relationship between the geological formation of the study area and the occurrence of the disease, it was observed that the entire study area is covered with Obusum and Oti beds. There are isolated sections of the Upper Voltain occurring in parts of the study area, namely parts of Central Gonja, Savelugu-Nanton, and Gushiegu districts. The widespread distribution of Obusum and Oti beds in the former guinea worm endemic areas of the region led to the conclusion that there was a direct relationship between the occurrence of Obosum and Oti beds geological formation and GWD.

There is an extensive distribution of Obusum and Oti beds in areas where the disease was not known. This was the case in the Mamprusi, Konkomba, and parts of the Bimoba and Komba areas. The non-occurrence of the disease in these areas gave rise to a counter conclusion of there being no relationship between geological and hydro-geological formations of these areas and the absence of the disease.

Studies by Carrier, Lefebvr, Racicot, and Asare (2008), Agyekum in Applegreen (2004), and Acheampong (1998), were used to explain the availability of underground water in some parts of the Northern Region and the scarcity of underground water in other parts of the region. Hydrogeological provinces in Ghana have been determined on the basis of geology (Bannerman, 1990; Acheampong, 1998). This was found to influence ground water occurrence and availability. The major hydrogeological provinces in the Northern Region are the Voltain Province and the Precambrian Province. Table 2 describes the content of these provinces with their corresponding dominant lithologies. An examination of these systems based primarily on the Voltain Province and the Precambrian Province revealed that spatial variability and quality of underground water is influenced by the dominant lithologies in each province (Carrier et al., 2006).

Rocks of the Precambrian Province possess low primary porosity and permeability. The most productive area of groundwater in this province is the lower and upper part of the rock. They complement each other in terms of permeability and storage. Ground water control and flow is therefore influenced by secondary porosity. However, the Birimian System in this province is known to yield high quantities of groundwater (Carrier et al., 2006). Hand dug wells are therefore used to exploit shallow aquifers. These wells, however, do not yield water all year round. This causes rural populations to return to non-potable sources toward the end of the dry season.

Rocks of the Voltain Province are well consolidated and impermeable. Ground water in this province occurs and flows in fracture zones and along bedding planes 
because primary porosity of these rocks was destroyed through compacting of loose deposits into rock, and ground water depositing cementing material to form sedimentary rock. The Voltain system is also unsaturated in many areas and thus provides minor amounts of ground water locally (Acheampong, 1998). This is due to the fact that regolith of the Voltaian system was found to have stable compositions of clay (shale), quartz (sandstone), or soft un-metamorphosed mudstone which have the capacity to store water but does not readily give up water. Fractured rock aquifers in this province have low to moderate productivity. Conversely, the middle Voltaian series has within its lithology arkose or arkosic sandstone (Oti beds) which weathers more easily than quartz or clay minerals and so are able to store and give up ground water from shallow perched aquifers. As a result the regolith aquifer in some places have been tapped with shallow hand dug wells (Dapaah-Siakwan, Agyekum, \& Darko, 2006).

Because it is much more difficult to obtain water from the Upper Voltaian and parts of the Middle Voltaian series, depths of boreholes in this province are deeper than those of the Precambrian Basement Province. Boreholes in the Voltaian Province are drilled to depths that range from $45 \mathrm{~m}$ to $75 \mathrm{~m}$ (Applegreen, 2004). Carrier et al. (2006) have reported that some borehole depths in this province, because of low transmissivity and high resistivity, have attained depths of approximately $355 \mathrm{~m}$. To explain the variability of borehole yields and the low success rate of potable water supply in the Northern Region, Dapaah-Siakwan et al. (2006) concluded that water bearing structures were discrete entities with highly variable production rates. This supports the assumption that ground water occurrence in the Northern Region is largely controlled by geologic structures.

An examination of the geological map of the Northern Region showed that guinea worm endemic districts are located largely on Obosum beds of the Middle Voltaian series. These districts include Central Gonja, E. Gonja, Nanumba North, Nanumba South, Zabzugu-Tatale, Yendi, Tamale Municipal, Karaga, Tolon, Kumbungu, Savelugu-Nanton, and Gushiegu districts. Figure 6 shows the location of these districts on the Middle Voltaian series of the Voltaian Province. The Obosum beds of this series are unsaturated in many areas and therefore provides minor amounts of ground water. This series has in its dominant lithology high quantities of clay which prevents the flow of ground water. This results in high failure rates when bore holes and wells are sunk in these districts. 


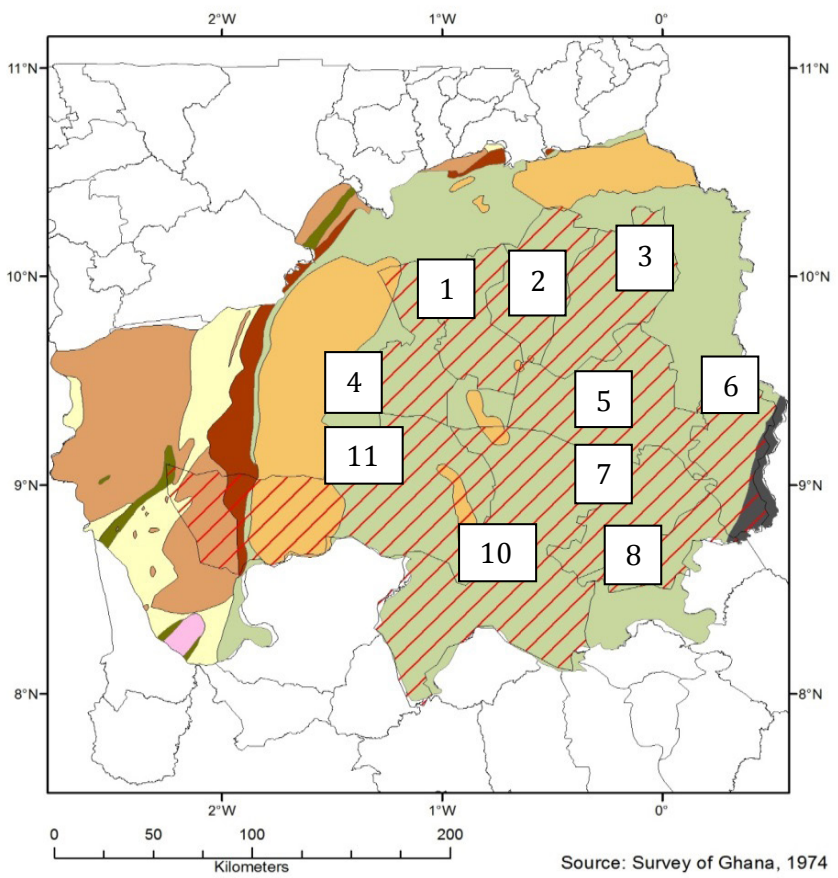

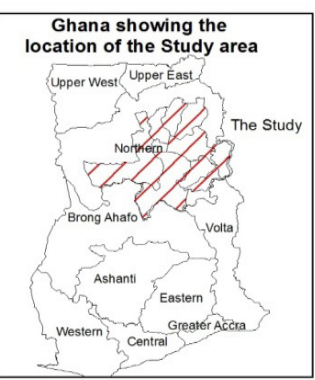

Legend

7 Study Districts geology

Basal Sandstone

Birimian Sediments

Birimian Volcanics

Buem

Dahomeyan

Obosum \& Oti Beds

Tarkwaian

Upper Voltaian

Districts boundaries

Savelugu-Nanton....1 Gushiegu......2 Karaga......3 Tolon..............4 Yendi......5 Zabzugu..................6 Nanumba North......7 Nanumba South.................8 Kumbungu......9 Central Gonja.......................10 East Gonja...............11

\section{Figure 6: Geological map of study area}


Table 2: Lithologies of major geological provinces of the Northern Region of Ghana

\begin{tabular}{|c|c|c|c|}
\hline Province & System & Series & Dominant Lithology \\
\hline \multirow[t]{5}{*}{ Voltain } & \multirow[t]{5}{*}{ Voltain } & Upper Voltain & $\begin{array}{l}\text { Massive sandstone, conglomerate } \\
\text { with thin beds of shale and } \\
\text { mudstone locally }\end{array}$ \\
\hline & & \multirow[t]{2}{*}{ Middle Votain } & $\begin{array}{l}\text { Obosum beds - mudstone, shale, } \\
\text { sandstone, conglomerate, some } \\
\text { limestone }\end{array}$ \\
\hline & & & $\begin{array}{l}\text { Oti beds - Arkose, sandstone, } \\
\text { conglomerate, mudstone, shale, } \\
\text { limestone }\end{array}$ \\
\hline & & Lower Voltain & $\begin{array}{l}\text { Basal quartz sandstone with pebbly } \\
\text { grits and grits }\end{array}$ \\
\hline & & Buem series & $\begin{array}{l}\text { Shale, sandstone, lava and full } \\
\text { with some limestone, grit, and } \\
\text { conglomerate }\end{array}$ \\
\hline \multirow[t]{5}{*}{$\begin{array}{l}\text { Precambrian } \\
\text { Basement }\end{array}$} & Tarkwaian & Huni, Tarkwa, Banket, Kawere & $\begin{array}{l}\text { Sandstone, shale, conglomerate } \\
\text { quartzite, schist, phyllite }\end{array}$ \\
\hline & \multirow[t]{4}{*}{ Birimian } & $\begin{array}{l}\text { Granitoid } \\
\text { intrusions }\end{array}$ & $\begin{array}{l}\text { Mainly granite, granodiorite, } \\
\text { gneiss }\end{array}$ \\
\hline & & $\begin{array}{l}\text { Granitoid } \\
\text { intrusions }\end{array}$ & $\begin{array}{l}\text { Mainly granite, granodiorite, } \\
\text { gneiss }\end{array}$ \\
\hline & & Upper Birimian & $\begin{array}{l}\text { Metamorphosed tuff and lava } \\
\text { (andesitic basaltic) }\end{array}$ \\
\hline & & Lower Birimian & $\begin{array}{l}\text { Schist, phyllite, slate, with } \\
\text { greywacke and sandstone }\end{array}$ \\
\hline
\end{tabular}

(Source: Carrier et al., 2006)

To see if there was a relationship between the geological structures in the Northern Region and the ethnic areas in which Guinea worm was endemic, the research examined the relationship between dominant lithologies of the geological formations and ethnic groups which are located in those areas. The ethnic areas which were isolated for this purpose were the Mamprusi, Dagomba, Gonja, Konkomba, and Nanumba areas. These areas are located on the Upper Voltain and Middle Voltain series of the Voltain Pronvince. The Upper Voltain was found to occur in large parts of the Mamprusi and Gonja areas. The Dagomba area was found to have minor distributions of this series. The Middle Voltain series was also found to cover extensive portions of the Mamprusi and Bimoba areas, the entire of Dagomba, Konkomba, and Nanumba areas, and extensive portions of the Gonja area (Carrier et al., 2008, 2009). 
As mentioned earlier, ground water of the Upper Voltain Province occurs and flows in fracture zones and along bedding planes. Secondly, the Middle Voltain has in the dominant lithology of its Oti beds, arkose or arkosic sandstone which weathers easily and is therefore able to store and give up ground water from shallow perched aquifers. The Mamprusi, Bimoba, and portions of the Gonja areas are endowed with this geological structure. This made it possible for these areas to benefit from shallow wells and relatively high success rates of sinking high yielding boreholes.

It is difficult to obtain ground water from Obosum beds of the Middle Voltain series because these geological structures are unsaturated in many areas of the region, thus providing insufficient amounts of ground water. Most of Dagomba, Konkomba, Nanumba and parts of Gonja are located on this geological formation. This condition makes it difficult for people in these areas to benefit from shallow wells and high yielding boreholes. This situation predisposed people in these areas to consider surface sources of drinking water as an alternative source of drinking water.

There was the suggestion that some inhabitants of former guinea worm endemic districts preferred surface sources of drinking water to ground sources. Some Gonja areas were reported to avoid water from boreholes because their ground water in their view was salty. Other areas which also have extensive distributions of Obusum and Oti beds were not reported to have a perceived report of high saline content from their ground sources of drinking water. This meant that not all water from Obosum and Oti beds was considered salty.

The above views were confirmed by Hunter (1996) who used West Africa's dry season of Northern Ghana to illiustrate how the difficulties of obtaining ground water in the Northern Region of Ghana makes populations in the area to become victims of water borne diseases, including GWD. Hunter (1996, pp. 1412) points out that "Tamale experiences a 5 month hot season. Over the dry season, total rainfall amounts to only $41.5 \mathrm{~mm}$. Under these desiccating conditions, families face serious dehydration, and must drink many litres of water daily. These necessary amounts increase if extra work activities are involved. The volumes of water that have to be consumed can be very large indeed. At a temperature of $35^{\circ} \mathrm{C}$ an adult requires $3-5$ litres per day; and if engaged in hard physical labour, this can rise to 8 - 11 litres daily. Such thirst inexorably leads to the consumption of pond water and virtually guarantees ingestation of Cyclops" (Hunter, 1996; Nwoke, 1992). Hunter (1996) notes further that despite increasing knowledge of causation, the imperative of thirst still generates imprudent behaviours. And that 'a man hard at work on a distant bush farm will take the risk and drink unsafe water from a pond. Later he [discovers] with dismay that he has contracted Dracunculiasis, despite living in a village that 
enjoys safe (borehole) water. Driven by thirst he had breached his own village water security.

\section{An Environmental and Cultural Examination of Guinea Worm Epidemic}

Attention was drawn to some environmental influences and cultural practices which contributed to the occurrence of the disease in the former guinea worm endemic areas of the region. During a key informant interview with the First National Guinea Worm Eradication Coordinator it was pointed out that there were cultural practices and environmental influences which accounted for the presence of the disease among some ethnic groups and its absence in others. Three reasons were advanced for the prevalence of the disease among the Gonja, Dagomba, Nanumba and Konkomba.

\section{The Environmental Perspective}

The Konkomba and Nanumba areas are located in the Nanumba North, Nanumba South and Zabzugu Tatale districts. It was observed that people in these areas were exposed to guinea worm infections because their major source of drinking water was from surface sources. The culture of digging wells was uncommon in these areas because their rivers and ponds provided them perennial supply of drinking water. Underground water was difficult to access because their water tables were so low as to render the cost of digging of wells expensive and unproductive. In these areas, transmission of the disease was influenced by interaction of people with their physical environment. That is having all year round contact with perennial surface sources of water as a result of have little access to wells in these areas. Boelee et al. (2009) confirmed the perennial contact with surface sources of drinking water argument of guinea worm transmission by reporting similar situations in Burkina Faso. Boelee et al, (2009, pp1) reported that "perennial and temporary reservoirs create new aquatic ecosystems ... where the presence of surface water ... may appear as a disturbing element. The establishment of small reservoirs is accompanied by important modifications of the local environment and changed ... behaviour of the benefitting population. Together, these factors may support the development of water-related diseases and subsequently lead to higher levels of endemicity or, in some cases even cause epidemics."

Also, in his Inherited burden of disease: agricultural dams and the persistence of bloody urine (Schistosomiasis hematobium) in the Upper East Region of Ghana, 1959-1997, Hunter (2003) presented the situation of water borne disease flaring up in Northern Ghana as a resulting of changed surface water conditions by stating that 'the northern 
Guinea Savanna woodlands presented a major challenge in Regional Development. The US Agency for International Development led with a vigorous developmental response that focused on the problem of water shortage. Earth dams were designed to serve small catchment areas at the village level. This resulted in the flare up of endemic parasitic disease'. This observation was confirmed by Hunter, Rey, and Scott's (1982) and Bugri's (1993) studies on Man-madelakes and man made diseases: Towards a policy resolutuion and Guinea worm Disease eradication and other concerns respectively where it was found that water borne diseases, including GWD are contracted from surface sources of water supply.

\section{The Cultural Context}

The interview with the key informant also revealed that the Gonja area had some endemic areas provided with boreholes; but the people preferred surface water to underground water. People therefore preferred surface sources of drinking water because of the high saline content of underground water and the low water table in the former Gonja guinea worm endemic areas which have extensive spatial coverage of Obosum and Oti beds and Upper Voltain formation. These factors influenced people in some Gonja areas to rely on surface sources of drinking water which exposed them to the disease. Bugri (1993) noted that peoples' perception of the taste of their underground water acted as a push factor to make them prefer surface sources of drinking water to water from boreholes.

For the Dagomba area the key informant intimated that the peoples' "knee deep" culture of fetching water from surface sources contributed to the spread of the disease. By this he meant there was the erroneous belief in some areas that good water could be obtained from surface sources by wading to "knee deep" level to fetch water. This exposure to surface sources of water made people in these areas to be exposed to the disease. Even though the Dagomba areas which were endemic to the disease are located on Obosum and Oti beds, there was no evidence of people in these areas avoiding water from ground sources because of their high saline content. However, there were complaints of aquifers being far removed from the surface, thus making the digging of wells laborious and in most cases unproductive. This belief was confirmed by Bugri (1993) who cited the erroneous belief of people in this area wading in surface water to knee deep level to fetch clean water as being another cause for the spread of the disease.

\section{The Non-Endemic Area}

In the case of non-endemic areas, it was revealed during the key informant interview that the Mamprusi and Bimoba areas managed to escape the guinea 
worm epidemic because of their culture of avoiding direct contact with surface sources of drinking water. This was done by digging shallow outlying wells close to surface sources of drinking water. The seepage of water from main surface sources of drinking water to outlying shallow wells automatically filtered their water of biologically infectious agents. By obtaining their water in this way the Walewale and Nalerigu areas managed to escaped the epidemic through the cultural practice of isolating biologically infectious agents of the disease by unconsciously filtering their surface sources of drinking water by using their bio-physical environment.

Hunter (1966) observed in his studies on onchocerciasis in the Upper Region of Ghana that "the pathway to diseases are geographical". That was to say the location of people in a particular geographical area and their way of life could predispose them to some form of disease. Their way of life could be influenced by climatic conditions and physical environmental characteristics. In Northern Ghana the dry season renders water in wells and ponds to dry up. This compels people to resort to ponds and dug outs for drinking water. This exposes them to the copepod of the disease because of their knee deep cultural belief and practice of fetching clean water from ponds and dug outs. In a similar way Hunter's argument could be said to hold true in avoiding disease by arguing that the pathway to avoid disease could also be geographical by transforming people's cultural practices and altering their interactions with their environment.

\section{Types of Drinking Water which Influenced the Spread of GWD in Northern Region}

Sources of drinking water which influenced the spread of GWD was examined with respect to sources of drinking water in the region before the GWEP was implemented. The study area had 483 potable and 2156 un-potable sources, and 593 potable and 2084 un-potable sources between 1970 and 1984 respectively (GSS, 2008-2017).

According to the census reports of the GSS (2008-2017) the major source of drinking water in the region in the 1970s was pipe borne water (38.8\%); followed by rain water (31.3\%); boreholes (28.4\%); with wells and surface sources coming last with $15 \%$ and $14.9 \%$ respectively. During the 1980 s the major source of drinking water was as follows: rain water (83.3\%); piped borne water (32.4\%); bore hole (28\%); surface sources of drinking water (27\%); and wells (17.9\%). These sources of drinking water were further classified into: potable and, surface sources. During the period under review it was found that the Northern Region relied more on surface sources (77.4\%) of drinking 
water than potable sources (22.5\%). Also, Saboba-Zabzugu registered the highest reliance of $46 \%$ on surface sources of

drinking water in the 1970s. In the 1980s Salaga and Bimbilla registered the highest reliance of $51 \%$ and $50 \%$ respectively on surface sources of drinking water. Areas with lowest reliance on surface sources of drinking water during the period under review was Tolon (28.9\%) for the 1970 and Tamale (29.3\%) for the 1980s. With regard to potable water it was found that areas that relied most on potable water in the 1970s were Walewale (17.7\%) and Tamale districts (17.3\%). In the 1980s Tamale district was found to have relied more on potable water (22.6\%). Implying that reliance on potable sources was found to be considerably lower than surface sources of drinking water (GSS, 20082017).

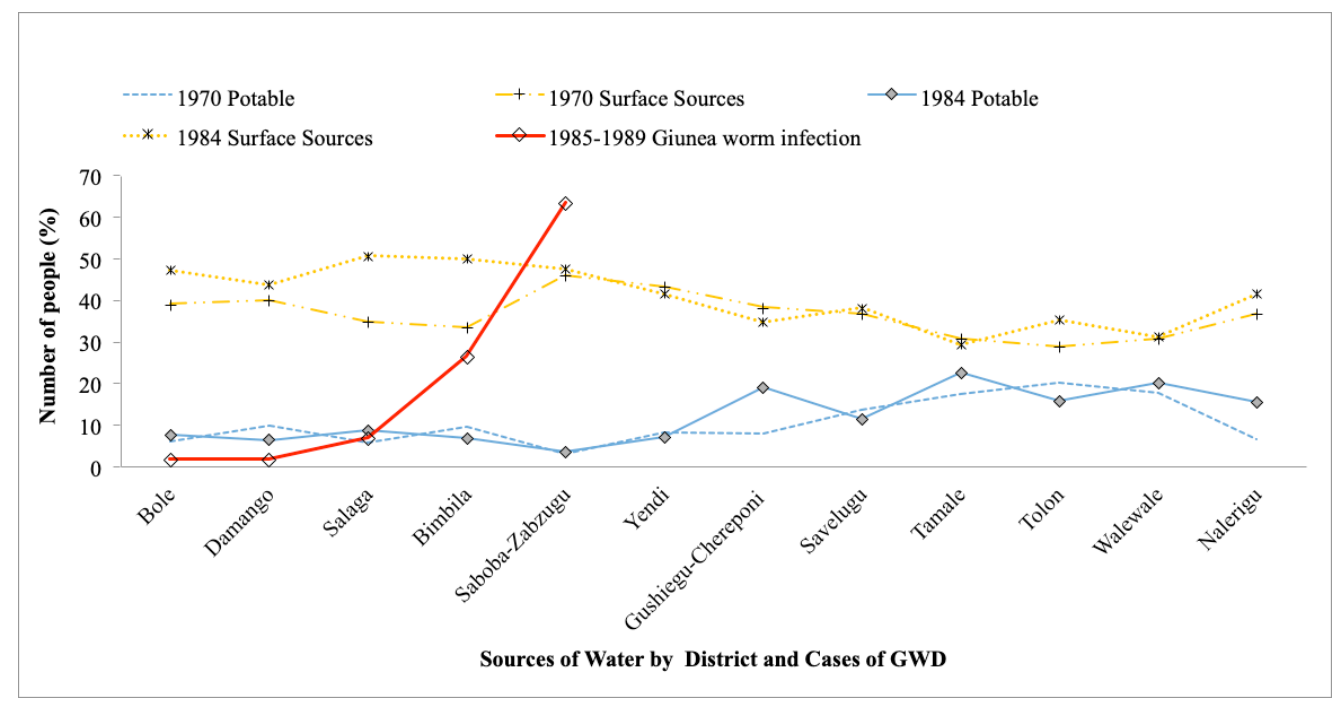

Figure 7: Sources of drinking water which influenced Guinea worm endemicity in the Northern Region between 1970 and 1989

Source: GSS (2008-2017) and GHS (2012)

In Figure 7 the number of reported cases of guinea worm infections in the region between 1982 and 1989 increased exponentially from $1.7 \%$ in 1985 through $6.4 \%$ in 1986 to $26 \%, 33 \%$, and 63\% between 1987 and 1989 (CDC, 1989).

The high reliance on surface sources of drinking water coupled with the exponential increase in the number of reported cases of the disease during the period under review, made it possible to infer that poor access to potable water and high reliance 
on surface sources played a major role in exposing residents of the region to the disease. This situation was readily understood for poor and rural communities in the region, considering the fact that most residents in urban communities in Ghana find it difficult to have access to water supply in their homes because cost of procuring such services was in their estimation expensive (Applegreen, 2004). The cost of providing potable water in the region from a geological and economic point of view was expensive and difficult to find ground water (Carrier et al., 2008).

Factors other than safe sources of drinking water which contributed to the spread of the disease in the region and the absence of it in other parts were cultural beliefs and practices, and climatic conditions. Even though the Savelugu, Gushiegu, and Tolon districts had the highest reliance on potable sources of drinking water, they recorded cases of guinea worm infection during the 1970s and 1980s. The explanation for the reported cases of guinea worm infections despite the presence of potable sources of drinking water in these areas was partly due to the "knee deep level" culture of drawing water from surface sources. This belief of drawing water from surface sources was the practice of wading to "knee deep level" to fetch "clean" water. This was due to the fact that water at the edge of ponds and dams was considered unclean because livestock disturbed the edges of surface sources of drinking water. And surface water located further from the edge was clean.

During FGDs in Gonja Traditional Areas which benefitted from the provision of potable sources of drinking water but were affected by the disease it was found that $75 \%$ (9) females and $42 \%$ (5) males making an overall proportion of $58.3 \%$ (14) of members of both focus groups indicated that they preferred water form rivers, wells, and ponds to borehole water. The reason they advanced to support their preference was that their borehole water was salty. Also, during FGDs in the Dagomba and Nanumba Tradtional Areas of Yendi, Zabzugu, Saboba, and Bimbila districts which had fewer boreholes and deep wells as compared to the Gonja Traditional Area had 38.5\% (37) females and 30.2\% (29) males, making an overall proportion of $68.75 \%$ (66) indicated that apart from getting their drinking water from boreholes and wells they rely on rivers, ponds, and springs during the dry season for their drinking water. This practice of getting drinking water from surface sources during certain times of the year exposed people in these areas to catching infections of guinea worm. These responses were supported with the GSS (2000-2017) report which indicated that between the 1970s and 1980s the Northern region relied less on potable sources of drinking water. For instance, the study area had $7.9 \%$ of the region's wells, $1.5 \%$ of the region's piped borne water, and $1.4 \%$ of boreholes. (GSS, 2008-2017). 
Despite the fact that Nalerigu had 1.4\% of the regions boreholes, $1.5 \%$ of the region's piped borne water, and $1.4 \%$ of the region's boreholes these districts hardly fell victim to GWD. A key informant interview revealed that despite the high reliance of these districts on surface sources of drinking water they have the culture of avoiding direct contact with surface sources of drinking water. The key informant explained that people in the Nalerigu and Walewale areas avoided coming into direct contact with surface sources by digging shallow outlying wells near bigger water bodies to draw their drinking water from them.

The key informant indicated that the Nalerigu and Walewale districts have a hydrogeological character of high water tables and a copious assemblage of permeable rocks which renders the digging of wells easy. Because of that these districts rely more on wells for their drinking water than areas in the Dagomba and Gonja Traditional Areas.

These factors on the causes of the disease indicates that a high dependence on unsafe sources of drinking water and a set of cultural practices, environmental conditions, climatic influences, and real or imagined perceptions on the taste of water influenced the survival and spread of the disease in the study area. The factors are confirmed by the findings of Hunter (1997) in his Geographical Pattern of Guinea Worm Infestation in Ghana: An Historical Contribution and Tayeh, Cairncross and Maude's (1993) work on Water Sources and Other Determinants of Dracunculiasis in the Northern Region of Ghana. These factors found expression in the hybrid conceptual framework of disease diffusion and disease ecology in Figure 1, where the agent-host factor relationship (biological, physical, and social factors) ensured the survival of infective larvae at the community level and, diffusing externally over time to cover wider geographic space. The social agent-host factor relationship that influenced the prevalence of the disease in the region was the perception of wading into ponds to 'knee deep levels' to draw good drinking water. This finding is confirmed by Hunter's (1981) work entitled Past Explosion and Future Threat: Exacerbation of Red Water Disease (Schistosomiasis haematobium) in the Upper Region of Ghana where disease transmission was found to occur as a result of social and economic factors of rural and agricultural areas with low economic status, poor housing, a lack of water supplies other than natural sources, substandard hygienic conditions, few sanitary facilities which bring the population in contact with water and transmission begins. In a similar vein the social agent-host factor relationship which prevented the disease from occurring in other parts of the region was the cultural practice of digging shallow outlying wells close to dams, ponds, and dugouts. 
Another social agent-host factor relationship which influenced the survival and spread of the disease was the real or imagined perception of the taste of underground water among people in the Gonja area. This perception acted as a push factor to make people in these areas to turn to surface sources of drinking water (See Plate 8) as an alternative, where without their knowledge, environmental conditions for the survival of infective larvae of the worm was suitable.

The physical environment agent-host factor relationship which influenced the survival and spread of the disease in some parts of the region was the prevailing environmental and climatic conditions which sustained the development of stagnant water bodies during the dry season, which people relied on as an alternative source of drinking water. This idea of the disease diffusing to cover wider geographic space stems from the fact that there have been reported cases of the disease being imported into the region from neighbouring Togo (Diamenu \& Nyarku, 1998).

The hybrid conceptual framework of disease diffusion and disease ecology was found to have the dual function of explaining the survival and spread of the disease to cover wider geographic space and, interrupting the chain of transmission of infective larvae between humans and their physical environment.

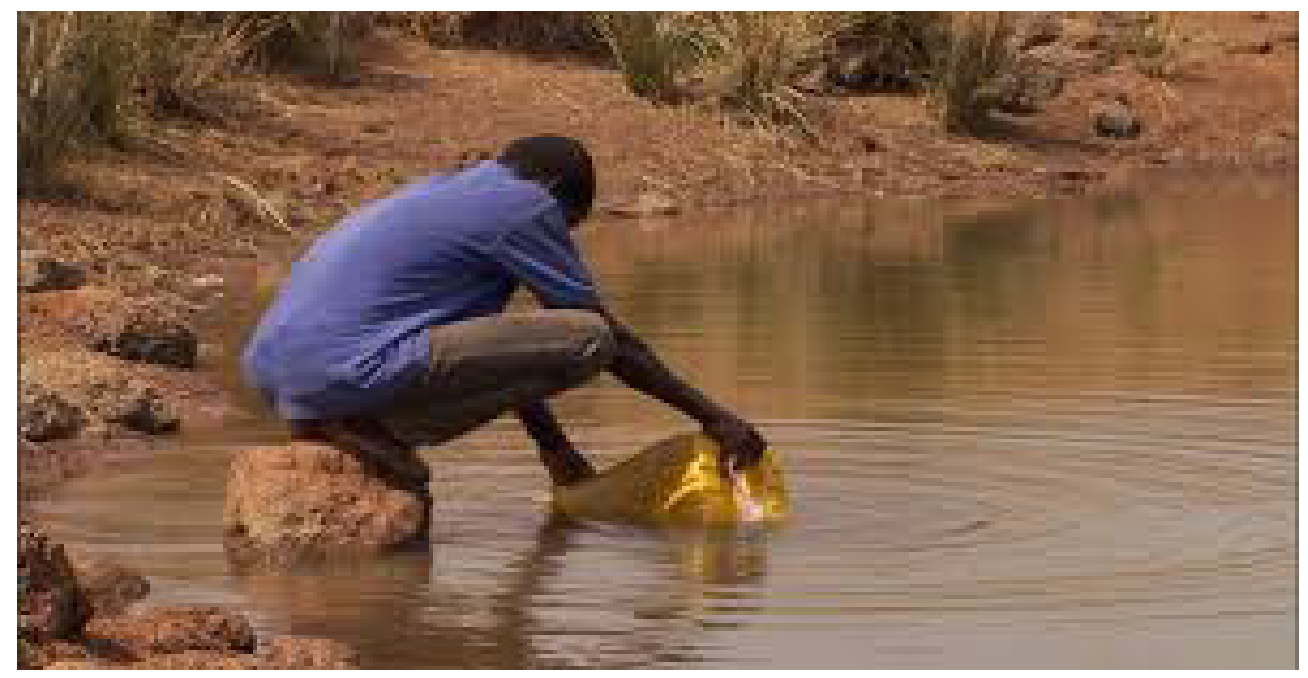

Plate 1: Reliance on Surface Sources of Drinking Water

Source: Courtesy of Guinea Worm Photo Gallery Ghana 


\section{CONCLUSION}

A set of cultural practices, environmental conditions, climatic influences, and real or imagined perceptions on the quality of water influenced the prevalence and spread of the disease in some parts of the region and, the absence of the disease in other parts. These factors found expression in the hybrid conceptual framework of disease diffusion and disease ecology, where the agent-host factor relationship (biological, environmental, and social factors) ensured the survival of infective larvae at the community level and diffused over time to cover wider geographic space in the guinea worm endemic districts. The social-agent host factor relationship which influenced and prevented the spread of the disease in the region was the culture of fetching water from ponds, the real/imagined perception of the taste of ground water which acted as a push factor to make people turn to surface sources of drinking water and the practice of digging outlying wells close to surface sources of drinking water. The physical agent-host factor relationship which influenced the survival and spread of the disease was the prevailing environmental and climatic conditions which sustained the presence of surface sources of drinking water in the dry season. The conceptual framework of disease diffusion and disease ecology was found to have the dual function of explaining the spread of the disease to cover some parts of the region and, the absence of it in other parts.

It was therefore concluded that the pathway to catching and avoiding guinea worm infections was cultural and behavioural because the way of life of some people, their climate and their physical environment make them vulnerable to the disease while the practice of digging outlying wells close to main surface sources of drinking water made others avoid the disease. This argument was advanced further by saying that the pathway to the condition of health of people could also be influenced by their culture and the nature of their bio-physical environment. In short a set of environmental factors and cultural influences caused the disease to spread in the Dagomba, Gonja, Nanumba and Konkomba areas, and the apparent absence of the disease in the Walewale and Nalerigu areas.

\section{RECOMMENDATIONS AND POLICY IMPLICATION}

It is recommended that government health institutions should make consistent efforts at developing innovative educational methods to expand the knowledge of rural people on the cause of disease and how to avoid them. Secondly, with respect to the overall health status of communities, public health organisations and their affiliate agencies should go the extra mile to note other disease conditions in communities and begin preliminary investigations into their socio-cultural causes. 
The government needs to make modest budgetary allocations to the Ministry of Health and its affiliate health institutions to finance the gathering of data on the general health condition of communities. This could lead to the discovery of diseases which, like GWD, went unnoticed and unattended to for a very long time. Initiatives aimed at unalterably reversing cultural beliefs and practices of avoiding direct contact with surface sources of drinking water should be implemented through collaboration with the Ministry of Health and Ministry of Tourism, Culture and Creative Arts.

Educational programmes aimed at making people in communities adopt the practice of wearing protective clothing when engaging in outfield domestic and socio-economic activities should be made an integral part of the country's national development agenda. The implication these recommendation will have on policy is that government will have to commit resources to provide people in rural areas with protective clothing (wellington boots and plastic gloves) for interacting with their biophysical environment, including surface sources of drinking water.

\section{References}

Acheampong, P.K. (1998). Water Balance Analysis for Ghana. Geography, 73(2), pp. $125-131$.

Applegreen, B. (Ed) (2004). "Groundwater resource of Ghana with focus on international shared aquifer boundaries" UNESCO-ISRAM Int Workshop Managing shared aquifer resources in Africa, Tripoli, Libya. June 2000, UN, IHP-VI Series on groundwater No. 8.

Bannerman, R.R. (1990. Appraisal of hydrogeological conditions and analysis of boreholes in the Nanumba and West Gonja Districts, Northern Region, Ghana, Ghana. Final Report for Rural Action. NORRIP/GTZ, April 1990.

Boelee E.; Cecchi P. and Koné P. (2009). "Health Impacts of Small Reservoirs in Burkina Faso.” Colombo, Sri Lanka: International Water Management Institute. 5op. (IWMI) Working Paper 136). doi:10.3910/2009.202 http://www.iwmi.cgiar.org/ Publications/Working_Papers/working/wp136.pdf.

Bugri, S.Z. (1981). Guinea worm an indicator of the quality and quantity of rural water supply in Northern Ghana (Dissertation). The Ross Institute, London Institute of Tropical Medicine and Hygiene.

Bugri, S.Z. (1993). Guinea Worm Disease eradication and other concerns. Water sanitation, Environment and Development Community-based surveillance in GWEP Ghana. 
Carrier, M.-A., Audibertt, R., Lefebvre, R., Racicot, J., Asare, E.B. Fontaine, R. and Rivera, A. (2009). Interim Hydrogeological Atlas. Hydrogeological Assessment Project of the Northern Regions of Ghana. Accra, Ghana.

Carrier, M.A, Lefebvre, R, Racicot, J, and Asare, E.B. (2008). Northern Ghana: Hydrogeological assessment project. Access to sanitation and safe water: Global partnerships and local actions. $33^{\text {rd }}$ WEDC Int. Conference, Accra Ghana.

Carrier, M.A, Racicot, J, Asare, E. B. Lefebvre, R. and Rivera, A. (2006) Bibliographical Review of Selected Papers - Hydrogeological Assesment Project of the Northern Regions of Ghana. Unpublished Report.

Centres for Disease Control (1989). Guinea worm wrap-up no. 23, no 27. WHO Collaborating Centre for Research, Training and Control of Dracunculiasis.

Centres for Disease Control (2005). Guinea worm wrap-up no. 150, no 153. WHO Collaborating Centre for Research, Training and Control of Dracunculiasis

Centres for Disease Control (2016). Guinea worm wrap-up no. no 238. WHO Collaborating Centre for Research, Training and Control of Dracunculiasis.

Creswell, J.W. (2009). Research design qualitative, and mixed methods Approaches, 3rd Edition. London: Sage Publications, pp.194-201.

Dapaah-Siakwan, S., Agyekum, W. and Darko, P. (2006). Borehole Drilling and Installation of Divers for Groundwater Monitoring in the White Volta River Basin. Council for Scientific and Industrial Research (CSIR) Water Research Institute. Accra, Ghana.

Diamenu, S.K. and Nyaku, A.A. (1998). Guinea Worm Disease - A chance for successful eradication in the Volta Region, Ghana. Soc. Sci. Med. 47(3), pp. 405-410.

Ghana Statistical Service. (2013). 2010 Population and Housing Census. National Analytical Report.

Ghana Statistical Service. (2008-2017). Ghana - Population Census 1970. GHA_1970_ PHC_vo1_M. Available at: www.statsghana.gov.gh.

Ghana Statistical Service. (2008-2017). Ghana Population Census 1984. GHA_1984_ PHC_vo1_M. Available at: www.statsghana.gov.gh.

Ghana Statistical Service, (2013). 2010 Population and Housing Census Report: NonMonetary Poverty in Ghana. Accra, Ghana: Ghana Statistical Service.

Ghana Guinea Worm Eradication Programme/Ghana Health Service. (2012). Ghana Guinea Worm Eradication Programme: Number of Cases by Region (1989-2011) Annual Report. 
Hunter, J.M. (1966). River blindness in Nangodi, Northern Ghana: A hypothesis of cyclical advance and retreat, Geographical Review, 56(3), pp. $398-416$.

Hunter, M.J. (1981). Past Explosion and Future Threat: Exacerbation of Red Water Disease (Schistosomiasis haematobium) in the Upper Region of Ghana. Geojournal 5: 305-313.

Hunter, J.M.; Rey, L. and Scott, D. (1982). Man-made lakes and man-made diseases. Towards a policy resolution. Social Science and Medicine, 16:1127-1145.

Hunter, M.J. (1996). An Introduction to Guinea Worm on the eve of its departure: Dracunculiasis Transmission, Health Effects, Ecology and Control. Soc. Sci., 43(9), 1399-1425.

Hunter, J.M. (1997). Geographical pattern of guinea worm infestation in Ghana: an historical contribution. Social Science and Medicine, 44(1), 103- 122.

Hunter, M.J. (2003). Inherited burden of disease: Agricultural dams and the persistence of bloody urine (Schistosomiasis haematobium) in the Upper East Region of Ghana, 1959-1997. Social Science and Medicine, 56: 219-34.

Isaev, L.M. (1956). Guinea worm and its eradication from Uzbekistan. Proc. Uzbekistan Inst. Malaria Med. Parasitol. (Samarkand) II: 3-14.

Johnston, R.J., Gregory, D, Pratt, G and Watts M. (Eds) (200o). The Dictionary of Human Geography, $4^{\text {th }}$ Edition.

Krejcie, R.V. and Morgan, D.W. (1970). Determining sample size for research activities. Educational and Psychological Measurement, 30: 607-610.

Kwei, C.A. (1997). Evaluation of groundwater potential in the Northern Region of Ghana. Report for the Canadian Internatinal Development Agency, March 1997.

Laari P.B., Kpieta B.A. and Aabeyir R. (2013). Towards guinea worm Eradication in Savelugu-Nanton District, Ghana: A spatio-temporal Approach. International Journal of Scientific \& Engineering Research, 4(9), 1001 - 1012.

Lucas, O.A. and Giles, H.M. (1973). A short textbook on preventive medicine for the Tropics, London, the English Universities Press Limited.

Nwoke, B.E. (1992). Behavioural aspects and their possible uses in the control of dracontiasis (guinea worm) in Igwun river basin area of Imo state, Nigeria. Angwandte Parasitologie 33(4) 205-210.

Stock, R.F. (1976). Cholera in Africa, Great Britain, Clarke Doble and Brendon Ltd. 
Tayeh, A., Cairncross, S. and Maude G.H. (1993). Water sources and other determinants of dracunculiasis in the Northern Region of Ghana. J. Helminthol, 67(3), 213225 .

Waddy, B.B. (1956). Organization and work of the Gold Coast Medical Field Units. Trans. R. Soc. Trop. Med. Hyg., 50(4), 313-386.

World Health Organization. (1998). Dracuncculiasis eradication in Uzbekistan: country report. WHO/CDS/CEE/DRA/99.9. World Health Organization, Geneva, Switzerland. 